\title{
Peran Keluarga dalam Proses Disengagement Pelaku Teror di Indonesia
}

\author{
Dhestina Religia Mujahid \\ Fakultas Ushuluddin dan Dakwah, IAIN Surakarta, \\ Jl. Pandawa, Dusun IV, Pucangan, Kec. Kartasura, Kabupaten Sukoharjo, Jawa Tengah \\ religiamujahidah.92@gmail.com
}

\begin{abstract}
Abstrak
Proses disengagement pelaku teror mulai marak terjadi. Faktor disengagement sangat beragam. Penelitian ini dilakukan untuk mengetahui peran keluarga dalam disengagement pelaku teror. Peneliti menggunakan metode kualitatif dengan pendekatan naratif dan purposive sampling pada tiga orang laki-laki pelaku teror. Satu orang diantaranya terlibat dalam peristiwa Bom Bali 1, informan lain terlibat dalam jaringan MILF, dan informan terakhir adalah pelaku teror bom low explosive di sekitar tempatnya tinggal. Pengambilan data dilakukan dengan wawancara mendalam, observasi, telaah dokumen BAP dan buku harian, serta pemberitaan media massa. Triangulasi dilakukan dengan melibatkan significant other informan utama. Kredibilitas penelitian didapat melalui triangulasi, member checking, dan paper trail. Keluarga berperan penting dalam proses disengagement. Budaya kolektivis di Indonesia membantu pelaku meninggalkan jalan teror. Keluarga mendukung pelaku untuk memulai kehidupan baru disaat mereka bimbang atas aksi kekerasan yang dilakukan. Menjadikan keluarga sebagai partner merupakan solusi baru dalam program rehabilitasi teroris.
\end{abstract}

Kata kunci: disengagement; deradikalisasi; terorisme; peran keluarga; budaya kolektivis

\begin{abstract}
The terror disengagement process has begun to increase lately. Disengagement factors are very diverse. This research was conducted to determine the family role in the terrorist disengagement process. Researchers used qualitative methods using narrative approach and purposive sampling on three terrorists. One of them was involved in the Bali Bombing 1 event, another informant was involved in the MILF network, and the last informant involved in the terror of low explosive bombs around his residence. Data is collected using in-depth interviews, observations, review of the police investigation report documents and diaries, as well as mass media reporting. Triangulation was carried out involving the significant others from key informants. The credibility of the study was obtained through triangulation, member checking, and paper trail. The family has a significant role in the disengagement process. The collectivist culture in Indonesia helped the terrorist to leave the path of terror behind. The family supports their struggle to start a new life when they were feeling uncertain about their past terror act. Making the family as a partner is a new solution in the terrorist rehabilitation program.
\end{abstract}

Keywords: Disengagement, Deradicalization, Terrorism, the role of family, collectivist culture

\section{PENDAHULUAN}

Terorisme menjadi masalah global yang hingga saat ini belum dapat terselesaikan dengan baik. Seluruh ahli seakan berlomba-lomba untuk mengentaskan masalah ini sesuai dengan latar belakang keilmuan mereka masing-masing. Di dalam keilmuan psikologi, studi tentang disengagement pelaku teror tidak dapat dilepaskan dari teori identitas yang diusung oleh Tajfel pada tahun 1957 (Milla, 2009; Mujahid, 2017). Tajfel (dalam Mujahid, 2017) mengungkapkan bahwa setiap orang memiliki identitas sosial yang pada akhirnya dapat membuat mereka merasa menjadi bagian dari kelompok sosial tertentu, serta memiliki emosi dan meyakini kebenaran suatu nilai sesuai dengan kelompok sosialnya tersebut. Jika identitas sosial dalam diri seseorang lebih kuat daripada identitas personalnya, maka dia akan menilai sesuatu bukan karena dia 
melakukan analisis dengan akal, melainkan sesuai dengan pandangan kelompok. Milla (2009) mengungkapkan bahwa disengagement pelaku teror dapat dilihat dari keyakinan mereka akan kelompoknya. Jika pelaku ragu akan aksi kekerasan dan mulai menjauh dari ingroup, maka dapat dipastikan dia mengalami disengagement. Namun apabila pelaku masih memiliki kontak yang erat dengan ingroup, maka dapat dipastikan dia masih meyakini cara-cara kekerasan dan teror sebagai jalan jihad.

Studi dalam disengagement selama ini berfokus pada faktor internal dan eksternal pelaku teror. Faktor internal dapat dicontohkan sebagai keinginan pelaku teror untuk menikah, memiliki anak, bekerja, dan memiliki kehidupan selayaknya orang pada umumnya (Horgan, 2009). Sedangkan faktor eksternal seperti konflik dengan anggota kelompok mengenai cara kekerasan yang selama ini mereka pilih menjadi strategi jihad adalah faktor lain dalam disengagement pelaku (Horgan, 2009). Faktor internal dan eksternal memainkan peran yang cukup penting dalam disengagement. Faktor internal merupakan faktor pendorong dan faktor eksternal sebagai faktor penarik seseorang keluar dari aksi teror dan beralih ke jalan damai dalam memperjuangkan ideologi mereka (Bjorgo, 2009).

Sedikit berbeda dengan pendapat di atas, Harris dan Harris (2010) mengemukakan, bahwa terdapat tiga faktor seseorang meninggalkan jalan kekerasan, yaitu faktor normatif, faktor afektif, dan faktor ke-continue-an. Faktor normatif berkaitan dengan ideologi pelaku teror. Terjadi pergeseran pemahaman dan arah perjuangan pelaku, yaitu beralih dari penggunaan cara-cara kekerasan ke jalan damai dalam memperjuangkan ideologi jihad (Harris \& Harris, 2010). Contoh dari faktor normatif adalah konflik interen pelaku dengan ingroup, merasa dikekang oleh ingroup, atau ingroup tidak dapat meyakinkan pelaku akan jalan yang teror yang selama ini dipilih sebagai sebuah kebenaran. Faktor afektif berkaitan dengan kebimbangan dan keprihatinan pelaku melihat penderitaan korban yang tidak berdosa serta perasaan bersalah yang menggelayuti pikiran mereka (Imron, 2010; Jacobson, 2010). Faktor ke-continue-an berkaitan dengan hasrat pelaku untuk memulai kehidupan baru seperti layaknya manusia normal pada umumnya, seperti melanjutkan sekolah, mencari pekerjaan, membangun rumah tangga, dan memiliki anak.

Beberapa ahli sepakat bahwa kontak dengan outgroup atau figure musuh dapat menurunkan tingkat radikalisme pelaku teror (Garfinkel, 2007; Bjorgo, 2009 dan Choudhury, 2009). Kontak dengan mantan mentor atau teman yang memiliki pemahaman berbeda mengenai jihad dapat mendukung dan menguatkan tingkah laku damai (Garfinkel, 2007; Demant, Slootman, Buijs, \& Tillie, 2008; Jacobson, 2010). Sarwono (2012) mengemukakan, bahwa kekuatan senjata tidak dapat digunakan dalam pencegahan dan penanganan terorisme. Sebaliknya, dialog dari hati ke hati dengan pendekatan emosi dianggap lebih efektif dalam rehabilitasi pelaku teror (Hendropriyono, 2009; Sarwono, 2012). Pendekatan-pendekatan humanis yang dirasa lebih efektif salah satunya adalah dengan membangun kembali kedekatan pelaku dengan keluarga yang selama ini mereka anggap sebagai outgroup.

Melibatkan keluarga dalam proses rehabilitasi pelaku teror sebenarnya bukan merupakan terobosan baru. Beberapa negara telah melakukan hal ini. Jacobson (2010) menjelaskan bahwa Arab Saudi membuat kebijakan dengan menahan pelaku teror di lembaga pemasyarakatan yang dekat dengan keluarga mereka tinggal. Selain itu, pemerintah juga mewajibkan keluarga untuk menjenguk narapidana terorisme secara berkala. Pemerintah Arab Saudi juga mengizinkan narapidana teroris untuk menghadiri acara pernikahan atau kematian anggota keluarga mereka. Hal yang dilakukan oleh pemerintah Arab Saudi sebenarnya telah dilakukan lebih dulu oleh pemerintah Amerika Serikat dan Malaysia (Fink \& Hearne, 2008). Bahkan di kedua negara tersebut, keluarga diberikan konseling dan kursus untuk dapat bertahan hidup tanpa kepala 
keluarga yang ditahan karena kasus terorisme. Jerman menjadi negara yang juga mencontoh kebijakan ini. Pemerintah Jerman membuat kebijakan dengan membangun kembali kontak pelaku dengan keluarga yang sempat terputus saat mereka masih menganut paham teror dan kekerasan (Spalek, 2016).

Menjalin kontak dengan keluarga yang terputus terbukti efektif dalam disengagement pelaku teror. Pemimpin kelompok radikal menyadari bahwa kontak dengan keluarga dapat menurunkan komitmen mereka dalam melakukan aksi kekerasan dan pengeboman (Demant, dkk., 2008; Jacobson, 2010). Pemimpin kelompok radikal berusaha menjauhkan pelaku dari keluarga mereka agar tidak mengurangi komitmen dan agar pelaku semakin radikal (Rabasa, Pettyjohn, Ghez, \& Boucek, 2010). Keluarga yang memiliki pemahaman jihad yang berbeda dengan pelaku akan dianggap sebagai outgroup dan akan dimusuhi pelaku teror (Sarwono, 2012). Oleh karena itu, menghubungkan kembali pelaku teror dengan keluarga menjadi cara yang cukup jitu dalam rehabilitasi pelaku teror.

Penyusunan program rehabilitasi teroris perlu mempertimbangkan aspek budaya masyarakat setempat (Fink \& Hearne, 2008). Jaafar, Muhamad, Hanapiah, dan Afiatin (2008) mengungkapkan bahwa Malaysia dan Indonesia memiliki kesamaan karakteristik dalam tatanan keluarga. Lebih lanjut mereka mengungkapkan bahwa keluarga merupakan aspek penting bagi masyarakat Indonesia dan Malaysia. Negara-negara seperti Singapura dan Malaysia telah menggunakan pendekatan emosi dan menjadikan keluarga sebagai subjek dan pembahasan dalam rehabilitasi pelaku teror (Rabasa, dkk, 2010). Lebih lanjut Rabasa, dkk (2010) mengungkapkan bahwa Indonesia belum melibatkan keluarga dalam rehabilitasi pelaku teror. Oleh karena itu penelitian ini akan mencoba menggali mengenai peran keluarga dalam proses rehabilitasi pelaku teror. Diharapkan penelitian ini dapat dijadikan referensi dalam program rehabilitasi yang tentunya sesuai dengan kondisi sosial budaya masyarakat kita.

\section{METODE}

Penelitian ini menggunakan metode kualitatif dengan pendekatan naratif. Pendekatan ini dipilih karena peneliti ingin mendeskripsikan peran keluarga dalam proses meninggalkan jalan teror bagi informan sebelum dan setelah mengalami disengagement. Informan dalam peneitian ini dipilih secara purposive dengan kriteria informan utama terbukti pernah terlibat dalam aksi teror dan mendeklarasikan diri keluar dari jalan teror dalam memperjuangkan ideologi jihad. Kriteria lain informan dalam penelitian ini adalah teroris yang mengungkapkan bahwa keluarga menjadi alasan utama mereka untuk meninggalkan aksi.

Penelitian ini melibatkan tiga orang informan dengan karakteristik yang berbeda. Informan pertama adalah pelaku teror dalam kasus Bom Bali 1 berusia 54 tahun; informan kedua adalah teroris yang terlibat dalam jaringan MILF berusia 49 tahun; dan yang terakhir adalah teroris lokal dengan kasus bom low explosive berusia 23 tahun. Pengambilan data dilakukan di lembaga pemasyarakatan tempat informan di rehabilitasi dan di lingkungan tempat mereka tinggal. Observasi di lingkungan tempat informan tinggal dilakukan untuk dapat mengobservasi lingkungan fisik, sosial, dan budaya informan utama. Moleong (2011) mengemukakan bahwa peneliti dalam studi kualitatif berfungsi sebagai alat. Oleh karena itu, peneliti memutuskan untuk terlibat langsung secara simultan dengan informan dalam kesehariannya.

Analisis data dimulai dengan restorying proses disengagement pelaku teror kemudian memperinci tema cerita yang menyajikan pembahasan detail tentang peran keluarga bagi pelaku. Verifikasi temuan penelitian dilakukan dengan member checking dan triangulasi data pada significant others, yaitu kepada orang tua, istri, saudara informan penelitian (yang juga berperan sebagai mentor bagi salah seorang informan). Penelitian dilakukan atas sepersetujuan 
informan dan keluarga mereka. Semua informan yang terlibat dalam penelitian ini dirahasiakan identitas dengan menginisialkan data diri mereka.

\section{HASIL}

Uraian hasil dimulai dengan memaparkan profil singkat pelaku teror kemudian membahasnya berdasarkan kesamaan tema dari masing-masing informan.

\section{Informan Reza (Samaran)}

Reza adalah pria keturunan Arab. Saat ini Reza masih dibina di lembaga pemasyarakatan karena terlibat beberapa aksi teror di Indonesia seperti kasus Bom Bali 1 dan Bom Malam Natal tahun 2000. Reza pernah menjadi buronan internasional selama sebelas tahun. Reza memiliki seorang istri warga asli keturunan Filipina yang dikenalnya saat bergabung dengan kelompok MILF di Mindanao. Saat ini istri Reza seorang diri tinggal di sekitar lembaga pemasyarakatan karena hingga usia pernikahan ke-24 tahun mereka belum memiliki keturunan. Reza adalah anak pertama dari tiga bersaudara. Kedua adik laki-laki Reza sudah berkeluarga dan memiliki anak. Mereka rutin mengunjungi Reza satu bulan sekali karena tinggal tidak jauh dari kota tempat Reza dibina.

Reza digambarkan sebagai sosok kakak yang baik dan mampu menjadi teladan untuk adikadiknya (WIT1\&2.IU1.R.220-235). Nilai-nilai keislaman, kasih sayang, dan kerukunan dengan keluarga sudah diajarkan oleh ibu kepada Reza dan adik-adiknya sejak kecil (WIT1\&2.IU1.R.195-206). Namun semenjak bergabung dalam kelompok teror, Reza berubah menjadi pribadi yang tertutup kepada keluarga (WIT1\&2.IU1.R.279-289). Reza masuk dan terlibat dalam aksi teror karena diajak oleh sahabat kecilnya. Reza menganggap bahwa sahabatnya tersebut memiliki pemahaman agama lebih mendalam darinya, sehingga pantas untuk dipercaya. Saat ini Reza memutuskan untuk meninggalkan jalan kekerasan dan teror. Dia menjadi pelopor napi teroris yang mengikuti upacara bendera dan mengakui Pancasila sebagai dasar negara. Hal yang tidak mudah dilakukan oleh pelaku teror. Reza bahkan sempat mendapatkan teror dari napi yang masih radikal atas aksinya tersebut.

\section{Informan Dimas (Samaran)}

Dimas adalah adik dari pelaku trio Bom Bali 1. Dia tidak secara langsung terlibat dalam aksi teror di Indonesia melainkan tergabung dalam kelompok separatis MILF. Dimas juga merupakan kepala instruktur perakitan bom JI di Jawa (W1.IU2.D.44-45) serta kepala instruktur milisi Ambon dan Poso (W1.IU2.D.384-388). Dimas mengenal dunia teror karena peran kakak tertuanya bernama Andi. Andi adalah penasihat spiritual dalam kasus Bom Bali 1 sekaligus petinggi kelompok Jama'ah Islamiah Asia Tenggara. Sejak kecil, Andi sudah mengajarkan kepada Dimas dan kedua adiknya yang lain yang juga merupakan pelaku utama dalam Bom Bali 1 untuk membenci pemerintah yang tidak menggunakan hukum Islam sebagai dasar negara (WIT1.IU2.D.63-67). Selain memutuskan untuk meninggalkan jalan teror, Dimas saat ini juga membantu pemerintah Indonesia dalam kampanye program kontra-terorisme. Dimas bahkan mendapatkan penghargaan honorary police dari pemerintah RI atas usahanya tersebut. Tidak hanya Reza, Dimas dan keluarganya juga mendapatkan teror bom di rumah mereka atas kampanye kontra terorisme yang telah dia lakukan selama ini. Namun hal tersebut tidak menyurutkan tekat Dimas untuk berhenti mengkampanyekan program kontra-terorisme. Karena bagi Dimas, hal yang dilakukannya tersebut merupakan bentuk pertanggungjawaban atas kesalahan yang pernah dilakukan oleh dirinya dan keluarga besarnya pada masa lalu. 


\section{Informan Adit (Samaran)}

Adit adalah seorang siswa sekolah kejuruan yang terjerumus ke dalam aksi teror bersama beberapa teman sekolahnya. Dia adalah anak pertama dari tiga bersaudara yang berasal dari keluarga kurang mampu. Berbeda dari dua informan sebelumnya, Adit tidak memiliki kemampuan cukup untuk merakit bom. Dia hanya dapat merakit bom low explosive dengan mengandalkan tutorial dari internet. Adit mendapatkan bahan-bahan dalam membuat bom dengan iuran bersama teman-teman amaliyat (perjuangan) serta dipandu oleh seorang mentor dan $u s t a d z$. Keluarga dan lingkungan cukup kaget ketika mengetahui Adit terlibat dalam aksi teror karena dia dikenal sebagai seorang anak yang mudah bergaul dan tidak menunjukkan tanda-tanda radikal.

Adit aktif dalam kegiatan karang taruna, gotong royong RT, dan mengajar santri-santri TPA di masjid sekitar tempatnya tinggal sebelum bergabung dalam kelompok teror. Namun semenjak bergabung, Adit berubah menjadi pribadi yang tertutup, cenderung kaku, dan menganggap orang lain yang tidak sependapat dengannya sebagai musuh yang harus diperangi. Tidak jarang Adit bertengkar dengan ayah mengenai masalah agama (WIT.IU3.A.249-254). Adit masuk dan terlibat dalam aksi teror karena mendapat iming-iming surga dan dapat memberikan syafa'at (pertolongan) kepada tujuh puluh anggota keluarganya tanpa hisab. Pemahaman tersebut dia peroleh dari mentor dan guru spiritual. Adit mulai masuk ke kelompok teror karena ingin hijrah menjadi manusia yang lebih baik walaupun miskin harta. Dia ingin berkontribusi untuk umat dengan tenaga (WIT.IU3.A.476-480). Adit memutuskan meninggalkan jalan teror karena ingin memulai kehidupan baru dengan bekerja membantu perekonomian keluarga dan ingin mencari jodoh.

\section{Peran Keluarga dalam Disengagement Pelaku Teror}

Keluarga menjadi faktor utama dalam proses disengagement ketiga informan dalam penelitian ini. Reza mendapat dukungan dari kedua adiknya untuk bangkit memulai kehidupan baru sekalipun dia masih harus mendekam di penjara. Dia bersyukur kedua adiknya mau memaafkan dan menerimanya kembali serta mau menganggap istrinya sebagai keluarga (W1.IU1.R.1281-1282). Perkataan sang adik membuat Reza bergetar dan memikirkan kembali aksi teror yang telah dilakukan selama ini:

"Sekarang ini yang aku anggap, aku jadikan orang tua, yang aku jadikan imam itu kau. Jadi aku minta kau yang jadi imam kami" (W1.IU1.R.1295-1297).

Tidak hanya menerima Reza, adik-adik juga menerima istri Reza, wanita asli Mindanao Filipina. Reza terharu karena keluarga besar menawarkan diri untuk menjaga dan mendampingi istri Reza selama dirinya dipenjara (W1.IU1.R.1321-1326). Istri Reza mengontrak rumah di sekitar lapas. Jika kesepian di kontrakan, maka dia akan pergi ke rumah saudara-saudara Reza, bertemu dengan keponakan-keponakan yang sudah dianggapnya sebagai anak sendiri. Peran keluarga juga terlihat dengan mencarikan pengacara yang tepat agar Reza tidak divonis eksekusi mati seperti ketiga temannya dalam kasus Bom Bali 1 (WIT1\&2.IU1.O\&I.766-807). Reza tergolong suami yang romantis dan perhatian kepada istrinya dari awal pernikahan. Sekalipun berada dalam pelarian di hutan Mindanao, Reza tetap berusaha menjadi tulang punggung keluarga dan suami yang baik untuk istrinya. Istri Reza menggambarkan bahwa suaminya adalah sosok yang romantis:

"Dulu itu waktu awal-awal nikah kan Ji, Bang Reza bikinin rumah dari kayu gitu. Disampingnya ada sungai yang selalu mengalir gitu Ji. Jerniiih banget ji.. Airnya bagus banget! Romantis gitu walau dihutan. Adeemmm... Romantis banget, Ji" (WIT3.IU1.F.) 
Rasa sayang dan tanggung jawab Reza kepada istrinya juga terlihat dari komitmen Reza untuk merahasiakan aksi teror yang selama ini dia lakukan bersama teman-temannya. Hal ini dilakukan sebagai upaya antisipasi jika Reza tertangkap, maka sang istri tidak akan diadili karena mengetahui aksi suaminya tersebut (W2.IU1.R.368-369). Tanggung jawab Reza juga terlihat saat dia mengungsikan istrinya dari rumah ketika kondisi tempat pelarian dirasa tidak aman (W1.IU1.R.940-944; W2.IU1.R.355-363).

Ketika di penjara dan melihat sang istri ikut terlibat mencari nafkah, Reza merasa terharu. Reza merasa berdosa karena tidak dapat membersamai sang istri dan membuat istrinya ikut mencari nafkah (W1.IU1.R.982-991). Dia tetap menjaga keharmonisan dengan istri agar istrinya tidak merasa kesepian karena tinggal seorang diri di rumah kontrakan. Reza menanam mawar di depan kamar tahanan dan akan mempersembahkan mawar tersebut untuk istrinya ketika dia datang berkunjung.

Kontemplasi terjadi saat Reza menjadi buron MILF:

"Jadi aku, ketika selama di Filipina itu ada satu pikiran yang selalu menggelayut dalam pikiranku. ... disebuah negara Filipina, negara katolik nomor dua terbesar di benua Asia. ... pemerintahnya tidak sama perlakuannya ... seperti Indonesia terhadap umat Islam ... dan dia (istri) mau dengan siapa ... aku kaya ga tega.” (W1.IU1.R.404-416)

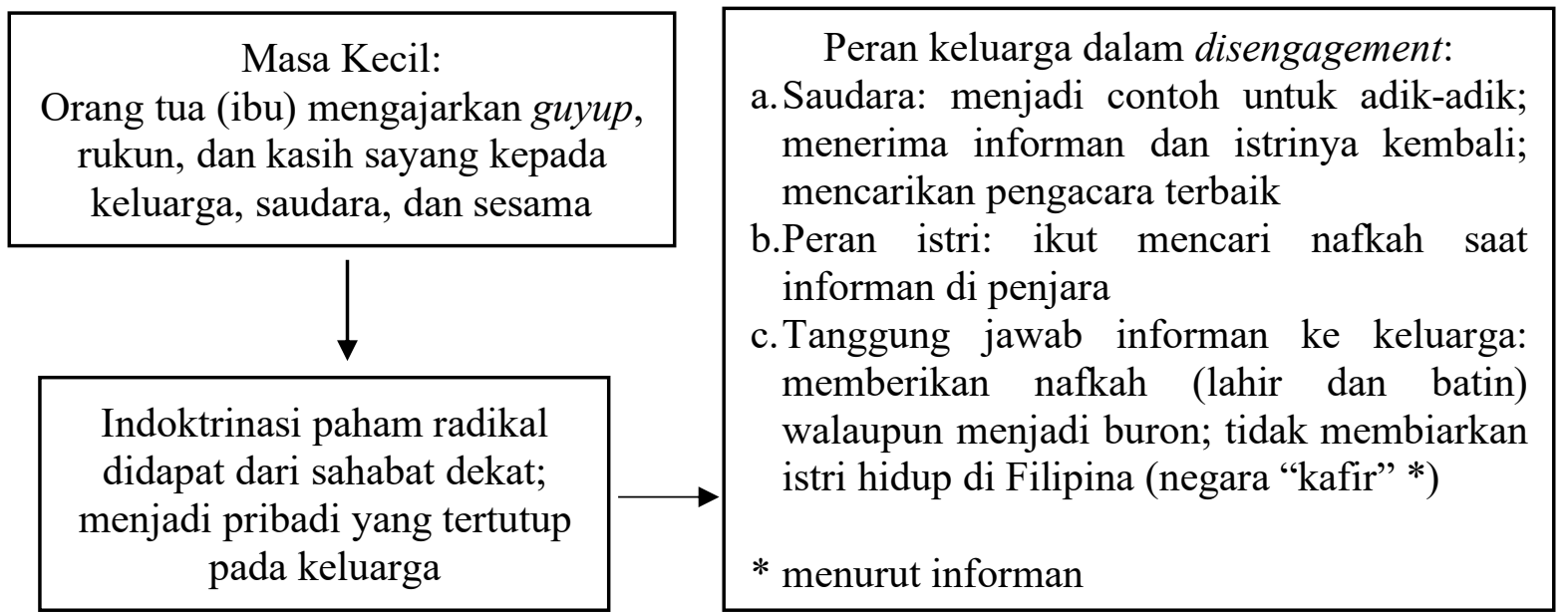

Gambar 1. Matriks Proses Radikalisasi dan Peran Keluarga dalam Disengagement pada Reza

Proses disengagement Dimas dimulai saat dirinya tertangkap oleh pemerintah Filipina untuk di pulangkan dan diadili di Indonesia. Saat itu dirinya mendapatkan nasihat dari kakaknya yang lebih dahulu telah memutuskan untuk meninggalkan jalan teror.

"Salah satu alasan saya meninggalkan dunia terorisme, faktor kakak saya. Mas Dodik. Ini masih di rutan, vonis seumur hidup. ... sebetulnya yang pertama kali mengubah kemauan saya. .... (kakak) nangis ketika saya dipulangkan. ... kuatir betul saya bergabung ke kelompok lama. ... Saya berjanji. Saya salah. Saya cinta aqidah saya, saya harus mengubah karakter saya." (W1.IU2.D.401-411)

Kakak yang selama ini menjadi sosok panutan dalam berjihad dengan cara kekerasan dan teror telah berpindah haluan dengan menyerukan program kontra-terorisme bersama BNPT. Dimas sangat menghormati sang kakak karena dia menganggap sang kakak lebih mengetahui ilmu agama daripada dirinya. Oleh karena itu, Dimas selalu meminta pertimbangan sang kakak atas segala keputusan yang menyangkut hidupnya, termasuk saat memutuskan untuk bergabung dan keluar dari keanggotaan JI. 
Kakak memberikan nasihat kepada Dimas untuk keluar dari kelompok teror (W1.IU2.D.668-669; WIT2.IU2.D.160-170). Dimas diminta oleh sang kakak untuk membantu dalam program pemerintah, yaitu deradikalisasi terorisme (WIT2.IU2.D.11-13; 216-222). Dalam upaya kampanye kontra-terorisme, Dimas berhubungan dengan outgroup termasuk BNPT dan aparat kepolisian yang notabene merupakan sosok yang dahulu dianggapnya sebagai musuh. Dalam masa kebimbangan, Dimas merasa bahwa pemerintah dan aparat penegak hukum tidak seburuk yang selama ini dia bayangkan. Dia bahkan diperlakukan sangat manusiawi oleh pemerintah walaupun telah terlibat dalam upaya radikalisasi pelaku teror (W2.IU2.D.33-38). Perlakuan manusiawi dari pemerintah dan aparat penegak hukum memang sudah Dimas dapat sejak dideportasi ke Indonesia (W1.IU2.D.628-629). Kedekatan dengan outgroup bahkan membuat Dimas sangat memuji salah seorang pejabat BNPT:

"Ini hanya karena kebaikan sosok Yusuf Natsir (nama samaran). Mungkin juga Mbak, tanpa Yusuf Natsir, ya Dimas bukan kayak sekarang ini.” (W2.IU2.D.232-233).

Dimas merasa nyaman dengan kegiatan barunya, yaitu dalam upaya kontra terorisme. Kampanye ini memang Dimas lakukan sebagai bentuk pertanggungjawaban atas kesalahan masa lalu (W1.IU1.R.1575-1578). Kakak menjadi sosok yang membantunya menemukan kehidupan baru yang lebih nyaman dan aman tanpa dia harus ketakutan menjadi buron. Dalam masa pelarian, tak jarang Dimas memikirkan nasib ibu dan juga istrinya. Pemakaman sang ibu tidak dapat Dimas hadiri karena dia menjadi buron. Dimas juga tidak dapat mendampingi istri ketika melahirkan anak-anak mereka. Semua hal tersebut membuat perasaan Dimas hancur dan dia tidak ingin hal itu terjadi kembali. Dimas ingin memulai kehidupan baru yang lebih damai dengan menebarkan kebaikan dalam memperjuangkan ideologi jihad.

Sosok kakak tidak hanya merangkul Dimas untuk keluar dari kelompok teror dan mengkampanyekan program deradikalisasi, tetapi juga membantu Dimas dalam menyusun materi kontra terorisme (WIT2.IU2.D.193-214). Selain itu, sang kakak juga menguatkan Dimas ketika dia dan keluarganya mendapat teror bom di rumah (WIT2.IU2.D.453-462). Kakak adalah sosok yang dapat memberikan nasihat dan memberikan kekuatan ketika Dimas sedang berada dalam masa-masa sulit dan menyemangatinya untuk terus mengkampanyekan program terorisme (WIT2.IU2.D.517-527).

\begin{tabular}{|c|c|}
\hline $\begin{array}{c}\text { Masa Kecil: } \\
\text { Sudah didoktrin untuk } \\
\text { membenci pemerintah } \\
\text { karena dianggap tidak dapat } \\
\text { mengakomodir hukum- } \\
\text { hukum Islam. Doktrin } \\
\text { ditanamkan oleh kakak } \\
\text { kandung yang lebih } \\
\text { superordinat. }\end{array}$ & $\rightarrow \begin{array}{c}\text { Nasihat dan dukungan dari kakak untuk } \\
\text { meninggalkan jalan teror dengan } \\
\text { mengkampanyekan program kontra- } \\
\text { terorisme bersama BNPT (outgroup) }\end{array}$ \\
\hline $\begin{array}{c}\text { Menjadi pembicara kontra-terorisme } \\
\text { Bersama BNPT. Hidup baru yang lebih } \\
\text { tenang dan damai }\end{array}$ \\
\hline
\end{tabular}

Gambar 2. Matriks Proses Radikalisasi dan Peran Keluarga dalam Disengagement Dimas

Adit adalah informan utama ke tiga yang melalui proses disengagement karena mendapat dukungan keluarga, terutama ibunya. Ibu menjadi sosok yang paling tertekan melihat anak sulung yang dibanggakannya terlibat dalam kasus terorisme. Adit melihat ibunya sakit-sakitan semenjak dirinya ditangkap. Keluarga juga mendapatkan tekanan sosial dan dikucilkan dari 
lingkungan sekitar (W1.IU3.A.264-267). Hati Adit pilu mendengar penuturan adik perempuannya yang dipanggil oleh guru BK hingga menangis saat diintrogasi mengenai paham teror yang dianut sang kakak (WIT1.IU3.A.89-100). Dia berkontemplasi selama di lembaga pemasyarakatan:

“... ma'e sesek, kadang pingsan waktu awal-awal dulu. Mbokdhe kadang sakit. Mbah juga sering sakit. Terus habis ketangkep itu banyak yag sakit, simbah sakit. .... budhe kan itu yang sejak kecil ngasuh saya. Waktu didalem itu pernah kayaknya simbah sekali besuk saya, pucet banget ... saya tanya diem nggak ngomong apa-apa. Cuma ngliatin saya, ngliatin terus, mau pulang itu cuma meluk, nggak dilepas-lepas. "(W1.IU3.A.5358)

Adit merasa bertanggung jawab atas semua kekacauan yang telah terjadi. Sebagai anak lakilaki pertama dari keluarga kurang mampu, dia berjanji untuk membantu perekonomian keluarga setelah keluar dari lembaga pemasyarakatan.

“....saya kan mikir sendiri sebagai anak pertama, saya punya adik-adik. Sedangkan bapak sudah menuju ke masa tua. .... nggak sampai 3 tahun lagi udah mau pensiun. Saya harus bantu keluarga" (W1.IU3.A.99-112)

Dukungan dari saudara sepupu menguatkan tekat Adit untuk berubah. Adit merantau ke ibu kota untuk mengadu nasib dan membantu menopang perekonomian keluarga. Saudara sepupu membantunya mencari pekerjaan dan akhirnya Adit mendapatkan pekerjaan cukup layak di sebuah perusahaan ternama di ibu kota. Adit dapat membantu perekonomian keluarga misalnya dengan menguliahkan adik perempuannya. Saat ini adit sedang berjuang untuk mencari jodoh. Citra sebagai seorang mantan terpidana kasus terorisme tidak begitu saja dapat dihapuskan. Adit masih sering mendapatkan stigma buruk dari orang-orang sekitarnya. Ayah menjadi sosok yang menguatkan Adit untuk selalu optimis menatap dunia ke depan tanpa perlu menoleh masa lalu (W1.IU3.A.433-437). Adit bersyukur mendapatkan keluarga yang bersedia menerimanya kembali, sekalipun dirinya telah membuat kesalahan yang cukup besar (W1.IU3.A.507-508).

\begin{tabular}{|c|c|}
\hline $\begin{array}{l}\text { Sebelum indoktrinasi paham } \\
\text { radikal, informan adalah pribadi } \\
\text { yang supel dan mudah bergaul }\end{array}$ & $\begin{array}{l}\text { Kontemplasi informan: } \\
\text { a. Ibu sakit-sakitan memikirkan nasib informan } \\
\text { b. Keluarga besar dikucilkan di lingkungan } \\
\text { masyarakat }\end{array}$ \\
\hline$\downarrow$ & $\begin{array}{l}\text { c. Anak pertama dan ingin membantu } \\
\text { perekonomian keluarga }\end{array}$ \\
\hline $\begin{array}{l}\text { Saat indoktrinasi : menjadi } \\
\text { pribadi yang tertutup dan } \\
\text { keras. Awal mula bergabung } \\
\text { hanya ingin berhijrah } \\
\text { menjadi lebih baik }\end{array}$ & $\begin{array}{l}\quad \text { Peran keluarga dalam disengagement: } \\
\text { a. Keluarga menerima informan kembali } \\
\text { b. Dukungan ayah untuk memulai kehidupan baru } \\
\text { c. Dukungan sepupu untuk mencari pekerjaan }\end{array}$ \\
\hline
\end{tabular}

Gambar 3. Matriks Proses Radikalisasi dan Peran Keluarga dalam Disengagement Adit

\section{DISKUSI}

Keluarga memiliki peran penting dalam doktrinasi maupun deideologisasi pemahaman jihad pada ketiga informan utama dalam penelitian ini. Keluarga yang memiliki pemahaman jihad dengan jalan kekerasan akan menguatkan proses radikalisasi pelaku teror (Milla, Faturochman, Ancok, 2013). Hal ini sangat jelas terjadi pada Dimas. Dimas mendapatkan 
doktrin jihad dengan jalan kekerasan sejak kecil. Keluarga dan lingkungannya adalah orangorang yang membenci pemerintah karena dianggap tidak menggunakan hukum Islam dalam tatanan bernegara. Dia hidup di lingkungan homogen, sehingga tidak ada pihak yang membuka wawasannya bahwa pemerintah sebenarnya banyak mengadopsi prinsip dan syariat Islam dalam merancang hukum dan peraturan perundang-undangan, sekalipun tidak menerapkan hukum Islam secara sempurna.

Keluarga yang memiliki pemahaman berbeda mengenai jihad akan terlibat konflik dengan pelaku yang masih radikal. Hal ini terjadi karena pemimpin kelompok telah mendoktrin pelaku bahwa orang yang berada di luar kelompok dan memiliki pemahaman jihad yang berbeda dengan mereka adalah outgroup yang harus dihindari dan diperangi. Pemimpin kelompok teror menyadari bahwa kontak dengan keluarga dapat melemahkan indoktrinasi mereka pada pelaku teror (Jacobson, 2010). Oleh karena itu, pemimpin akan berusaha menjauhkan pelaku yang sedang didoktrin dari keluarga mereka dengan cara memprofokasi konflik antara pelaku dengan keluarga dan lingkungan sosialnya (San, Siekelinck, \& Winter, 2013). Sarwono (2012) mengungkapkan, bahwa pelaku teror adalah pribadi yang jauh dari keluarga. Lebih lanjut, Mujahid (2017) mengungkapkan bahwa doktrin jihad tersebut yang pada akhirnya akan membuat pelaku lebih mementingkan perkataan pemimpin dan misi kelompok daripada kepentingan pribadi maupun keluarganya.

Dibesarkan dalam budaya kolektivis menjadi salah satu faktor yang mempermudah proses rekonstruksi pemahaman jihad informan utama dalam penelitian ini. Keluarga menjadi aspek penting bagi masyarakat dengan budaya kolektivis (Jaafar, dkk., 2008). Keputusan menerima informan kembali sekalipun telah mempermalukan nama baik keluarga dan dukungan untuk memulai kehidupan baru menggerakkan hati pelaku untuk meninggalkan jalan kekerasan dan teror. Pendekatan humanis dengan dialog dari hati ke hati yang keluarga lakukan terbukti dapat menggetarkan hati pelaku. Gunaratna \& Hassan (2011) mengungkapkan bahwa penggunaan kekerasan tidak lagi efektif dalam penanganan terorisme. Namun dialog beradab dengan menggunakan pendekatan emosional lebih efektif dalam pengentasan terorisme (Sarwono, 2012).

Berikut merupakan gambaran peran keluarga dalam proses disengagement informan utama dalam penelitian ini:

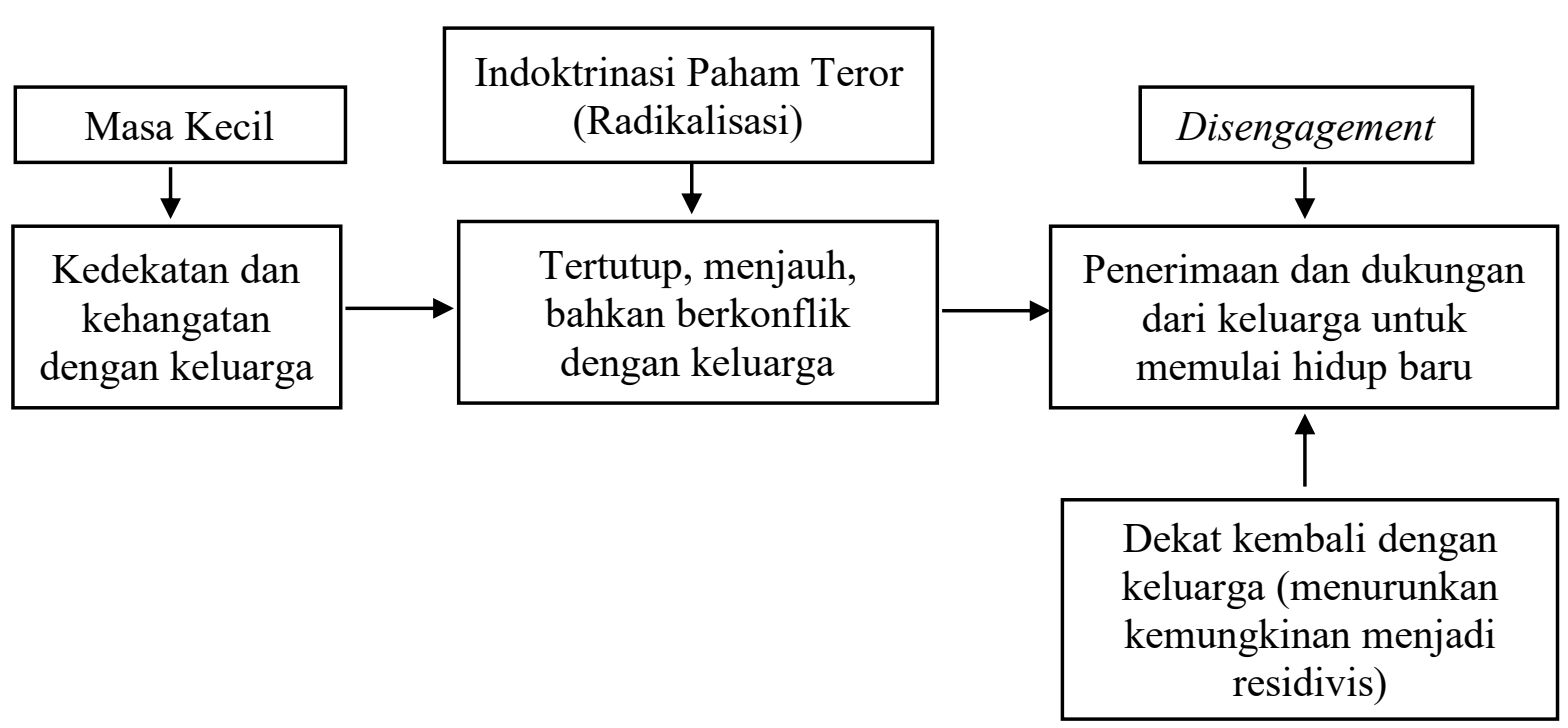

Gambar 4. Peran Keluarga dalam Disengagement Pelaku Teror 
Menghubungkan kembali pelaku dengan keluarganya terbukti dapat membantu proses disengagement informan dalam penelitian ini. Guru (2012) dan Jacobson (2010) mengungkapkan, bahwa proses disengagement pelaku teror akan lebih mudah dilakukan jika informan dapat dihubungkan kembali dengan keluarganya. Kontak dengan keluarga yang memiliki pemahaman jihad berbeda dengan pelaku menjadi salah satu indikator keberhasilan program rehabilitasi. (Demant dkk, 2008; Jacobson, 2010; Spalek \& Davies, 2012). Dapat disimpulkan demikian karena pelaku yang masih radikal tidak akan menjalin kontak yang cukup intens dengan outgroup, sekalipun keluarga mereka sendiri (Disley, Weed, Reding, Clutterback, \& Warnes, 2012; Sarwono, 2012). Mempertahankan kontak dengan keluarga dapat memperkuat tingkah laku damai informan. Hal tersebut dapat terjadi karena keluarga akan memberikan dukungan ketika informan terpuruk dan mendapatkan ujian disaat ia memulai kehidupan baru.

\section{KESIMPULAN}

Dukungan keluarga berperan cukup penting dalam proses disengagement pelaku teror. Keluarga yang tidak menyetujui aksi informan akan memberikan wawasan baru mengenai jihad yang sesungguhnya, yaitu bukan jihad yang dibenci dan menodai citra Islam. Keluarga mulai berperan cukup penting dalam proses disengagement pada pelaku teror jika pelaku mulai ragu dan bersalah akan jalan kekerasan dan pengeboman yang mereka pilih. Karakteristik masyarakat Indonesia dengan budaya kolektivis yang cukup dekat dengan keluarga dapat dijadikan pertimbangan dalam menyusun upaya rehabilitasi pelaku teror agar program tersebut dapat berjalan dengan efektif.

\section{DAFTAR PUSTAKA}

Bjorgo, T. (2009). Processes of disengagement from violent groups of the extreme right. In T. Bjorgo \& J. Horgan (Eds.), Leaving terrorism behind: Individual and collective disengagement (pp. 30-48). Oxon: Routledge.

Choudhury, T. (2009). Stepping out: Supporting exit strategies form violence and extreme. Washington DC: Institute for Strategic Dialogue.

Demant, F., Slootman, M., Buijs, F., \& Tillie, J. (2008). Decline and disengagement: An analysis of processes of deradicalisation. Amsterdam: Institute for Migration and Ethnics Studies.

Disley, E., Weed, K., Reding, A., Clutterback, L., \& Warnes, R. (2012). Individual disengagement from Al-Qaida-influenced terrorist groups. Santa Monica CA: Rand Corporation.

Fink, N. C., \& Hearne, E. B. (2008). Beyond terrorism: Deradicalization and disengagement from violent extremism. London: International Peace Institute.

Garfinkel, R. (2007). Personal transformations: Moving from violence to peace. Washington DC: United States Institute of Peace.

Gunaratna, R., \& Hassan, M. F. (2011). Terrorist rehabilitation: The Singapore experience. In R. Gunaratna, J. Jerard, \& L. Rubin (Eds.), Terrorist rehabilitation and counterradicalisation: New approach to counter terrorism (pp. 36-58). New York: Routledge.

Guru, S. (2012). Under siege: Families of counter-terrorism. British Journal of Social Work, 42, 1151-1173. doi:10.1093/bjsw/bcs089.

Harris, K. J. (2011, January). Review: Disillusionment with radical social groups. Paper 
presented in Australian Counter Terrorism Conference, Perth, Western Australia. Abstract retrieved from http://ro.ecu.edu.au/act/4/

Hendropriyono, A. M. (2009). Terorisme fundamentalis Kristen, Yahudi, Islam. Jakarta: Kompas.

Horgan, J. (2009). Individual disengagement: A psychological analysis. In T. Bjorgo \& J. Horgan (Eds.), Leaving terrorist behind: Individual and collective disengagement (pp. 17-29). New York: Routledge.

Imron, A. (2010). Ali Imron sang pengebom. Jakarta: Republika.

Jaafar, J. L. S., Muhamad, H., Hanapiah, S.A., Afiatin, T., \& Sugandhi, Y.S. (2008). The index of happiness of the Malaysian and Indonesian people. Proceedings Asia in Transformation: Exploring New Values in Asia, 1, 1-15.

Jacobson, M. (2010). Terrorist dropouts: Learning from those who have left. Washington: The Washington Institute for Near East Policy.

Milla, M. N. (2009). Dinamika psikologis pelaku terorisme: identitas dan pengambilan keputusan jihad di luar wilayah konflik pada terpidana kasus bom Bali di Indonesia (Tesis tidak terpublikasi). Fakultas Psikologi Universitas Gadjah Mada, Yogyakarta.

Milla, M.N., Faturochman, \& Ancok, D. (2013). The impact of leader-follower interactions on the radicalization of terrorists: A case study of the Bali bombers. Asian Journal of Social Psychology, 16, 92-100. doi: 10.1111/ajsp.12007.

Moleong, L. J. (2011). Metodologi penelitian kualitatif. Bandung: PT. Remaja

Mujahid, D.R. (2017). Dinamika Disengagement Pelaku Terorisme di Indonesia (Tesis tidak terpublikasi. Fakultas Psikologi Universitas Gadjah Mada, Yogyakarta.

Rabasa, A., Pettyjohn, S. L., \& Jeremy J., \& Ghez, C. B. (2010). Deradicalizing islamist extremists. Santa Monica CA: Rand.

San, V. M., Siekelinck, S., \& Winter, M. D. (2013) Ideals adrift: An educational approach to radicalization. Ethics and Education 8(3), 276-289. doi: 10.1080/17449642.2013.878100.

Sarwono, S. W. (2012). Terorisme di Indonesia dalam tinjauan psikologi. Jakarta: Alfabet.

Spalek, B. (2016). Radicalisation, de-radicalisation, and counter-radicalisation in relation to families: Key challenges for research, policy, and practice. Security Journal, 29, 39-52. doi: $10.1057 /$ sj.2015.43.

Spalek, B., \& Davies, L. (2012) Mentoring in relation to violent extremism: A study of role, purpose, and outcomes. Conflict and Terrorism Studies, 35(5), 354-368. doi: 10.1080/1057610X.2012.666820. 